\title{
Long term treatment of polymyalgia rheumatica with deflazacort
}

Marco A Cimmino, Gianluigi Moggiana, Carlomaurizio Montecucco, Roberto Caporali, Silvano Accardo

\begin{abstract}
Objectives-To evaluate the long term efficacy and tolerability of deflazacort, a corticosteroid reputed to have only minor side effects, in the treatment of polymyalgia rheumatica (PMR).

Methods-In a prospective open study, deflazacort was administered at an average initial dose of $21.8 \mathrm{mg} /$ day for a mean period of 19 months in 40 patients with PMR.

Results-A highly significant improvement of clinical and laboratory parameters occurred one month after therapy onset. This improvement persisted for the whole study period. Laboratory parameters of tolerability did not change during the study. Mild to moderate steroidrelated side effects occurred in $57.9 \%$ of the patients

Conclusions-Deflazacort is effective in the treatment of PMR. Its long term safety profile may be superior to that of other corticosteroids.
\end{abstract}

(Ann Rheum Dis 1994; 53: 331-333)

Polymyalgia rheumatica (PMR) is a disease of the elderly that causes pain and stiffness of the limb girdles, fever, weight loss, and an elevation of non-specific indicators of inflammation. ${ }^{1}$ Corticosteroids are its treatment of choice. They control the symptoms of most patients and may prevent serious ocular complications when giant cell arteritis is associated. However, prolonged use of corticosteroids can result in multiple side effects.

The efficacy and tolerability of deflazacort, a derivative of prednisone, ${ }^{2}$ was evaluated in PMR. Deflazacort is generally associated with milder bone damage than other corticosteroids $^{3}$ and with minor effects on glucose metabolism. ${ }^{4}$

\section{Patients and methods}

We studied 40 consecutive outpatients with active PMR diagnosed according to Jones and Hazleman. ${ }^{5}$ Only patients older than 50 years with an erythrocyte sedimentation rate (ESR) greater than $40 \mathrm{~mm} /$ hour were included. ${ }^{6}$ They had not received steroids and gave their informed consent.

Deflazacort was administered at a mean starting dose of $21.8 \mathrm{mg} /$ day with a range of 6-60 mg depending on severity of disease. The most common starting doses were $15 \mathrm{mg} /$ day (15 patients, $37.5 \%$ ), $30 \mathrm{mg} /$ day (14 patients, $35 \%$ ), and $6 \mathrm{mg} /$ day (four patients, $10 \%$ ). The highest dose $(60 \mathrm{mg}$ ) was used in two patients with concomitant giant cell arteritis. Patients were evaluated monthly for one year and every six months thereafter. Deflazacort was tapered by about $20 \%$ if the patient was asymptomatic and ESR was reduced. Side effects were searched with a questionnaire and by physical examination.

In PMR recurrences (defined as signs or symptoms of PMR and/or giant cell arteritis requiring higher doses of steroids), deflazacort was increased to the latest level that had kept the patient asymptomatic. A relapse was defined as signs or symptoms of PMR requiring corticosteroid therapy after its discontinuation.

Statistics included one-way ANOVA, Student's $t$ test, chi-square test with Yates' correction and the Kaplan-Meier method for survival curves. All the tests were two-tailed. The 'post-hoc comparison' was evaluated by the least significant difference method.

\section{Results}

PATIENTS

The mean age of the 40 patients (24 women/ $16 \mathrm{men}$ ) was $70 \cdot 7$ years (range $50-91$ years). Patients were referred 4.6 months after the onset of PMR on average (range 1-14 months).

Twenty seven patients were allowed to continue treatment with NSAIDs at low doses. Of these, 15 received NSAIDs for less than three months and 12 for 9.7 months in average. The dose of NSAIDs in these 12 patients was constant throughout the study.

FOLLOW UP

Two patients were lost to follow up on the first and third month. In the remaining 38 patients, the treatment lasted a mean of 18.9 months (range 9-48 months). Of the 23 patients with remission, seven required deflazacort for less than one year, and 20 for less than two years (fig 1). In these patients, the mean follow up after discontinuation of deflazacort was $9 \cdot 9$ months (range 1-33 months). The mean daily dose of deflazacort was $11.4 \mathrm{mg}$ (range $2 \cdot 5-3.2 \cdot 2 \mathrm{mg}$ ) and the cumulative dose ranged between $0.9 \mathrm{~g}$ and $27 \mathrm{~g}$ (mean $6.6 \mathrm{~g}$ ).

Twenty three of 38 patients $(60.5 \%)$ had no exacerbations; 13 patients had one exacerbation, 
1 had two and 1 had four. Except for two cases of frank temporal arteritis, exacerbations were mild. All exacerbations could be controlled by a temporary increase of deflazacort. No relapses were seen in $21 / 23(91 \cdot 3 \%)$ patients. Only two patients had relapse two months after discontinuing deflazacort.

\section{CLINICAL EFFICACY}

The visual analogue scale of pain $(F=20.9$, $\mathrm{p}<0.00001)$ and the duration of morning stiffness $(F=42.3, p<0.00001)$ decreased at one month of follow up and on the subsequent control visits (fig 2 ).

LABORATORY DATA ON TREATMENT EFFICACY ESR was raised in all patients (mean $72.9 \mathrm{~mm} /$ hour, range $40-114 \mathrm{~mm} /$ hour) on the baseline values. After one month, the mean ESR value was $30.6 \mathrm{~mm} /$ hour $(t=10.95, p<0.00001)$. In the following months, ESR further decreased $(\mathrm{F}=32.58, \mathrm{p}<0.00001)$ (fig 2). CRP $(\mathrm{F}=8.4$, $\mathrm{p}<0.00001)$ and alpha-2-globulins $(\mathrm{F}=6.8$, $\mathrm{p}=0.00001)$ also decreased; haemoglobin increased $(F=5 \cdot 3, p=0.0002)$.

\section{CLINICAL TOLERABILITY}

No significant changes in mean blood pressure took place during treatment. Hypertension ( $25 \mathrm{~mm} / \mathrm{Hg}$ over baseline values) was observed

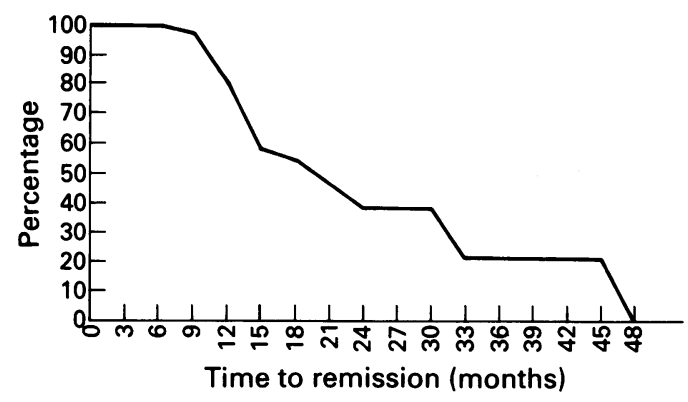

Figure 1 Kaplan-Meier survival curve showing the time of cessation of treatment because of onset of remission (used as end point) in the study population.

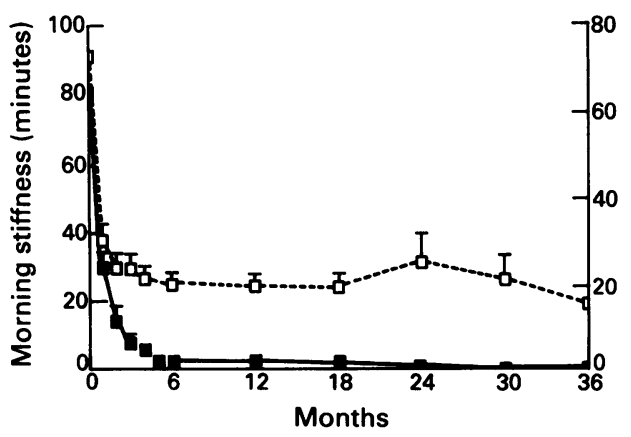

Figure 2 Changes (+SEM) in the mean duration of morning stiffness (solid squares; solid line) and in mean ESR (open squares; dashed line) during deflazacor treatment of patients with polymyalgia rheumatica. Differences from baseline values of morning stiffness were highly significant in month $2-24(p<0.00001)$ and for months 1 and 30-36 $(p<0.0001)$. Differences from baseline values of ESR were highly significant on months through $18(p<0.00001)$ and for months 30 and 36 $(p<0.001)$. in five patients who were not taking NSAIDs; in three, hypertension was present on the first visit. It was controlled by antihypertensive therapy.

The average body weight reported by the 40 patients before the onset of PMR was $68 \mathrm{~kg}$ (range $43 \cdot 5-114.5 \mathrm{~kg})$. It was $66 \cdot 1 \mathrm{~kg}(\mathrm{t}=3 \cdot 83$, $\mathrm{p}<0.0004)$ at the first visit. During treatment, weight increased $(F=1.43, p=0.1956)$ but did not reach pre-disease levels.

LABORATORY DATA ON DRUG TOLERABILITY

The mean white blood cell count, the mean lymphocyte count, as well as the mean serum total protein concentration, transaminases, urea, creatinine, sodium and potassium remained unchanged throughout the study.

The mean platelet count $\left(339 \times 10^{9} / \mathrm{L}\right.$ at baseline) decreased significantly during follow up $(F=2.42, p=0.041)$. However, all values remained within normal range.

The mean serum fasting glucose was normal throughout the study, despite a significant decrease seen on the six month control visit $(5.28 v 4.97 \mathrm{mmol} / \mathrm{L}, \mathrm{t}=2.26, \mathrm{p}=0.032)$.

SIDE EFFECTS

Thirty six side effects occurred in 22/38 $(57.9 \%)$ patients (table). These were present in $17 / 23(73.9 \%)$ women and in $5 / 15(33.3 \%)$ men (chi-square $=4.58, \mathrm{p}=0.032$ ).

There was no significant difference in age, initial deflazacort dose, mean daily deflazacort dose, concomitant use of NSAIDs, and number of exacerbations or relapses between patients with adverse effects and those without. In the first group, treatment was longer [mean (SD) $21.9(11.4) v 14.7(4.7)$ months, $\mathrm{t}=2.39$, $\mathrm{p}=0.022]$ and the mean (SD) cumulative dose higher [7910 (5716) gm $v 4708(2226) \mathrm{gm}$, $\mathrm{t}=2 \cdot 12, \mathrm{p}=0 \cdot 041]$.

\section{Discussion}

The efficacy and tolerability of deflazacort has not been tested on a long term basis in patients with PMR. In a recent double-blind study comparing deflazacort with prednisone in

Side effects of deflazacort treatment in patients with polymyalgia rheumatica

\begin{tabular}{llcc}
\hline Side effect & $\begin{array}{l}\text { Number of } \\
\text { patients }\end{array}$ & $\begin{array}{l}\text { Mean interval } \\
\text { (months) }\end{array}$ & $\begin{array}{l}\text { Mean } \\
\text { cumulative } \\
\text { dose (mg) }\end{array}$ \\
\hline Weight gain & 7 & $8 \cdot 6$ & 4479 \\
Cystitis & 7 & $12 \cdot 9$ & 5532 \\
Hypertension & 5 & $10 \cdot 6$ & 6248 \\
Dyspepsia & 4 & $3 \cdot 0$ & 1445 \\
Tachycardia & 3 & $15 \cdot 3$ & 7050 \\
Fracture & 2 & $5 \cdot 0$ & 3982 \\
Diarrhoea & 2 & 6.5 & 2126 \\
Exacerbation & 2 & 17.5 & 4342 \\
of cataract & 2 & $15 \cdot 0$ & 14850 \\
Exacerbation & 1 & $1 \cdot 0$ & 980 \\
of diabetes & 1 & $8 \cdot 0$ & 9540 \\
Nausea & 1 & 33.0 & \\
Vertigo & 1 & &
\end{tabular}

Of the 22 patients who experienced a side effect, 11 had one side effect and the other 11 had two or more side effects. $\star$ Time between beginning of side effect. 
chronic inflammatory disorders, two patients with PMR have been treated with deflazacort for three months with a good response. ${ }^{2}$ In another short term trial, ${ }^{7}$ Lund et al tested patients with PMR for the relative antiinflammatory potency of deflazacort versus prednisone. These authors concluded that the potency of deflazacort expressed on a weight for weight basis was less than that of prednisone. The median dose of $15 \mathrm{mg}$ of deflazacort we used is equivalent to a value of $8.3 \mathrm{mg}$ to $12.5 \mathrm{mg}$ of prednisone on an equimolar basis. ${ }^{7}$ This relatively low dose of deflazacort reduced both symptoms and objective parameters of disease activity in PMR.

We found a recurrence rate of polymyalgic symptoms of $39.5 \%$. It is lower than the reported values of $56 \%{ }^{8}$ and $108 \cdot 5 \%{ }^{9}$ with other steroids but similar to the $37.5 \%$ value of Kyle and Hazleman. ${ }^{10}$ Accordingly, also the relapse rate of $8.3 \%$ is lower than the reported values of $35 \cdot 8 \%,{ }^{11} 35 \cdot 1 \%,{ }^{8}$ and $25 \cdot 7 \% .{ }^{9}$ Under reporting of late relapses may have occurred in our study because the follow up after deflazacort withdrawal was only 9.9 months on average. However, one year after completion of the study, none of the patients returned to the clinic because of a relapse.

In our patients, median treatment was 20 months. With different corticosteroids it was $37 \cdot 3$ months $^{8}$ and $25 \cdot 7$ months. ${ }^{12}$ These observations suggest that deflazacort has an anti-inflammatory effect that is at least comparable to that of prednisone.

The number of patients who experienced at least one side effect was 22/38 (57.9\%), compared with a reported prevalence of $68 \cdot 1 \%$ or another of $81 \%{ }^{10}$ with prednisolone. The latter study is the only prospective study on side effects of steroids in PMR. Two other studies report side effect prevalences of $7 \cdot 5 \%{ }^{12}$ and $22 \cdot 6 \%{ }^{8}$ Their retrospective design, however, may have biased interpretation of results because data were obtained from patients' records.

In all patients, body weight increased significantly after six and 12 months of treatment. However, if weight loss is considered a constitutional sign associated with untreated PMR, the mean weight did not exceed the pre-disease values reported by the patients.

The prevalence of bone fractures was lower $(5 \cdot 2 \%)$ than that of $13.5 \%$ observed in the $\mathrm{UK},{ }^{13}$ but comparable to those of $5 \cdot 8 \%{ }^{1}$ and $4 \%{ }^{8}$ in the USA. Vertebral fractures occurred after five months of treatment in two patients. Both patients reported bone fractures even before treatment with deflazacort.
Of the two patients with type II diabetes mellitus, one showed progression of the disease during treatment (fasting blood glucose previously normal on diet alone that increased to $8.6 \mathrm{mmol} / \mathrm{L}$ ). Diabetes was controlled by oral hypoglycaemic agents. New cases of diabetes mellitus were not observed during the study. Mean fasting blood glucose in the remaining patients decreased slightly on the six month control. This observation may be due to the patients' paying more attention to their diet after being informed about the risks of corticosteroid therapy.

In conclusion, deflazacort has antiinflammatory effects that are at least equivalent to those of prednisone in patients with PMR. Although no long term comparison with prednisone was performed, we propose that deflazacort is better tolerated. These considerations indicate the need for a controlled comparative trial. PMR constitutes a good model for this type of comparison because this disease has a typical, prompt response to corticosteroids and requires long term but usually definite treatment.

Dr Carlo M Pesce, Istituto di Anatomia Patologica, Università di Genova, kindly reviewed the early drafts of the manuscript.

1 Chuang T, Hunder G G, Ilstrup D M, Kurland L T. Polymyalgia rheumatica. A 10-year epidemiologic and clinical study. Ann Int Med 1982; 97: 672-80.

2 Gray R E S, Doherty S M, Galloway J, Coulton L, de Broe M, Kanis J A. A double blind study of deflazacort de Broe M, Kanis J A. A double blind study of deflazacort and prednisone in patients with chronic infla

3 Messina O D, Barreira J C, Zanchetta J R, et al. Effect of low doses of deflazacort vs prednisone on bone mineral content in premenopausal rheumatoid arthritis. f Rheumatol 1992; 19: 1520-6.

4 Bruno A, Cavallo-Perin P, Cassader M, Pagano G Deflazacort vs prednisone: effect on blood glucose control in insulin-treated diabetics. Arch Int Med 1987; 147: 679-80.

5 Jones J G, Hazleman B L. Prognosis and management of polymyalgia rheumatica. Ann Rheum Dis 1981; 40: 1-5.

6 Cimmino M A, Caporali R, Montecucco C M, Rovida S, Baratelli E, Broggini M. A seasonal pattern in the onset of polymyalgia rheumatica. Ann Rheum Dis 1990; 49: of polym $521-3$.

7 Lund B, Egsmose C, Jorgensen S, Krogsgaard M R. Establishment of the relative antiinflammatory potency of deflazacort and prednisone in polymyalgia rheumatica. Calc Tis Int 1987; 41: 316-20.

8 Ayoub W T, Franklin C M, Torretti D. Polymyalgia rheumatica. Duration of therapy and long-term outcome. Am ₹ Med 1985; 79: 309-15.

9 Lundberg I, Hedfors E. Restricted dose and duration of corticosteroid treatment in patients with polymyalgia rheumatica and temporal arteritis. 7 Rheumatol 1990; 17: $1340-45$.

10 Kyle V, Hazleman B L. Treatment of polymyalgia rheumatica and giant cell arteritis. I. Steroid regimens in the first two months. Ann Rheum Dis 1989; 48: 658-61.

11 Behn A R, Perera T, Myles A B. Polymyalgia rheumatica and corticosteroids: how much for how long? Ann Rheum and corticosteroids: $1983 ; 42: 374-8$.

12 Delecoeuillerie G, Joly P, Cohen de Lara A, Paolaggi J B. Polymyalgia rheumatica and temporal arteritis: a retrospective analysis of prognostic features and different corticosteroids regimens (11 year survey of 210 patients) Ann Rheum Dis 1988; 47: 733-9.

13 Kyle V, Hazleman B L. Treatment of polymyalgia rheumatica and giant cell arteritis. II. Relation between steroid dose and steroid associated side effects. Ann Rheum Dis 1989; 48: 662-6. 